
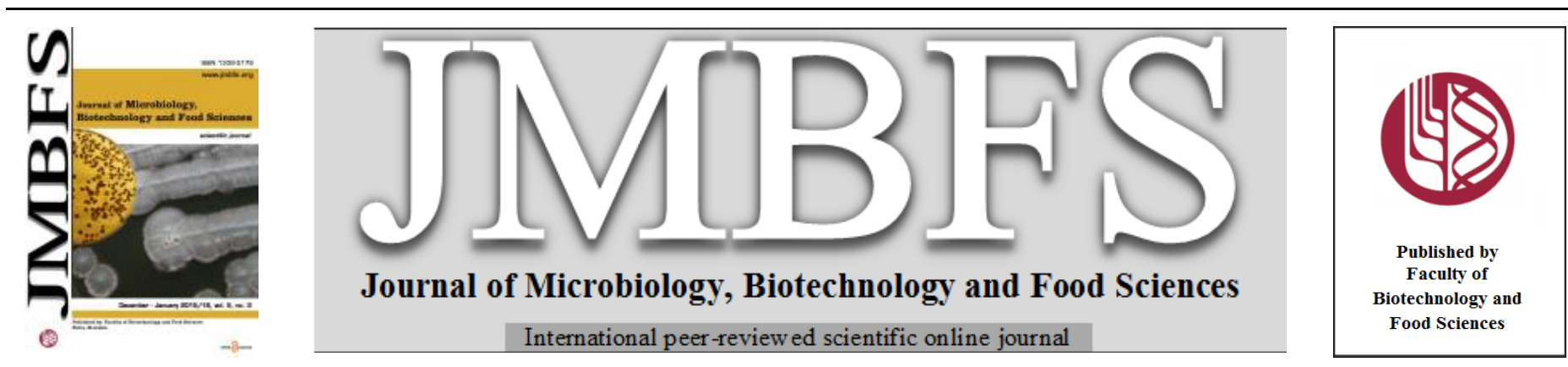

\title{
USE OF FLOUR-GRAPHICS TECHNIQUE IN THE COMPATIBILITY PARAMETER EXTENSOGRAPH BRABENDER AND FLOURGRAPH E7
}

\author{
Maria Lidia Iancu* and Mihai Ognean \\ $\operatorname{Address}(e s)$ : \\ "Lucian Blaga" University of Sibiu, Faculty of Agricultural Science, Food Industry and Environmental Protection, Department of Agricultural Science and Food \\ Industry, 5-7, Dr. Ion Ratiu street Romania tel.+04(0)269211338.
}

*Corresponding author: maria.iancu@ulbsibiu.ro

doi: $10.15414 / j m b f s .2015 / 16.5 .3 .277-281$

\section{ARTICLE INFO}

Received 24. 2. 2015

Revised 2. 10. 2015

Accepted 14. 10. 2015

Published 1. 12. 2015

Regular article OPEN $\partial_{\text {ACCESS }}$

\begin{abstract}
The flourgraphic technique used in the study of flour quality has led to the emergence of new devices. The devices used in the present study were Extensograph Brabender and Flourgraph E7 (new) and Flourgraph E6 (new) and the Farinograph Brabender. Constructive models is differs little and so appeared purpose of the studies, present objective. The objective of our study was to identify relationships between the values of measured variables characterizing such rheometric elements as: properties of dough formation and its viscoelastic properties. The values will be obtained, in parallel, with Extensograph Brabender and Flourgraph E7. Kneading the dough was made with Flourgraph E6 and Farinograph Brabender, respectively. Three types of flour were used in the study: semolina flour from durum wheat (F1), type 650 white wheat flour (F2), and type 000 white wheat flour (F3). Parallel determinations were made using the same method. The parameters obtained were energy $\left[\mathrm{cm}^{2}\right]$, resistance to extension [BU], [HE], extensibility [mm], maximum resistance [BU], $[\mathrm{HE}]$ ratio and maximum ratio. The values obtained were analyzed by applying a statistical algorithm which yielded very good correlation indices, generally ranging between 0.8 and 0.9 . The correlations were positive, strong and moderate. According to polynomial regression and strong positive correlations, which means that high $\mathrm{x}$ variable (determined from Extensograph Brabender) scores go with highly (determined from Flourgraph E7) variable scores and vice versa. This demonstrates that the two pairs of equipment used to assess the viscoelastic properties of dough are a good choice.
\end{abstract}

\section{INTRODUCTION}

In 1930 one of the first special instruments was designed for physical testing of wheat flour doughs, the so called Brabender Extensograph (Bloksma and Bushuk, 1988; Kahramam et al., 2008).

A few years later, C.W. Brabender (1934) introduced the extensograph in research laboratories of wheat flour quality control (Preston and Hoseney, 1998).

The extensograph was developed to evaluated the qualities that govern the behavior of dough at the fermentation stages and during its mechanical handling (Moss, 1980; Rapsen and Preston, 1991; Zaharia et al., 2014).

Measuring the tensile properties of dough is one of the most important techniques used to assess the quality of flours used for bread making. Müller presented in 1961 results of the analysis based upon the curve of the effort to stress. The difference between the resistance to extension for strong and weak flour are shown in the mass effective changes.

Rheological measurements are relevant tools in the food industry for physical characterization of raw material prior to and during processing, and of final food products (Tabilo-Munizaga et al., 2005). Flour can be classified according to extensograph results as "short", "buky", "extensible" or "pliable" (Rapsen and Preston, 1991). The extensograph can be used to study, pH action (Tanaka et al., 1967 b), influence of oxidants and related compounds (Bloksma and Bushuk, 1988), potato pulp (Iancu et al., 2011), of food fiber (Sharoba et al., 2013), and other materials, such as: ginseng (Song et al., 2007) and orange peel powder (Astha and Masih, 2014).

The quality parameters for the wheat flour dough were assessed with farinography, extensography, amylography and texture profile analysis (Bahareh et al., 2013). Rheological studies on the various factors influencing variables rheometer dough were made (Tong et al., 2010; McCann and Day, 2013).

The extensograph known in same countries, was conceived at a time on advances in the mechanization and automation of the baking process had created conditions that made the uniformy of ingredients, especially flour.
Haubelt Laborgerate GmbH was found in January of 2006. Haubelt has been designed to test rheological properties of wheat and wheat flour. The factory is producing rheological flour quality testing instruments called Flourgraph E6 and Flourgraph E7 (CFW, 2007). Flourgraph E6 and Flourgraph E7 have emerged on the profile market in 2010 (ICC Standard No. 179(E6), 180(E7)).

All of the above mentioned equipment have been internationally validated as references ICC standard since more than decades and since basic rheological instruments are capable of proving the essentials, or fundamental details of the materials rheological properties, ICC continuously struggles to study, validate and publish new standard methods for such equipment as the Haubelt Flourgraph E7(Jbeily et al., 2014 b). Thus using the Flourgraph E6, preparing dough for E7. For Flourgraph E6 and Flourgraph E7 were made research and concluded was that the values obtained for many flours studied and several laboratories (ring test) have described a linear regression i.e. Repeatability and reproducibility are good (Jbeily et al., 2014 a, b). Principle which is based on functioning of these devices in range Brabender and Haubelt is the same. Constructive models is differs little and so appeared purpose of the studies, present objective.

For statistical interpretation used The Pearson correlation coefficient measures the strength and direction of the relationship between two variables.

\section{MATERIAL AND METHODS}

Was used in the determination, semolina flour from durum wheat (Mill Cibin, Romania) had the following characteristics: moisture was determined (\%) (ICC Standard No. 110/1 (1976)) (13.6\%); wet gluten (\%) (ICC Standard No. 106/1(1976)) (32\%); gluten deformation (mm) (SR 90:2007) (3.2mm); gluten index (SR 90:2007) (58); Falling Number (s) (ICC Standard No. 107/1) (350s); titratable acidity $\left(\mathrm{SH}^{\circ}\right)\left(\mathbf{S R} 90\right.$ : 2007) $\left(2.1 \mathrm{SH}^{\circ}\right)$; water absorbtion from flour $(\%)$ (ICC-Standard 115/1, 1998, AACC Method 54-21, 1995, ICC- Standard-180, 2010) (53\%), the white flour type 650 (Mill TITAN, România) had the following characteristics humidity $13.9 \%$; wet gluten $32 \%$; gluten deformation $4 \mathrm{~mm}$; gluten index 55.68; Falling Number 290-300s; titratable acidity $2.2 \mathrm{SH}^{\circ}$, water 
absorption from flour 56,9\%, used same method like semolina flour durum wheat, ash content $(\%)$ (ICC Standard No. 104/1, (1990)) (0.649\%); and the white flour type 000 (Mill Boromir, România) had the following characteristics humidity $14.5 \%$; wet gluten $29 \%$; gluten deformation $5.5 \mathrm{~mm}$; gluten index 49 ; Falling Number 330s; titratable bile acidity $2.3 \mathrm{SH}^{\circ}$; ash $0.480 \%$; water absorbtion from flour $55 \%$, utilizing the same methods

For dough rheological characteristics was used Farinograph Brabender (Duisburg, Germany) (AACC Method 54-21, 2000) characteristics were determined according to the AACC Method. The following parameter were determined in a Brabender farinograph was water absorbtion (\%) of water required to yield dough consistency of $500 \mathrm{BU}$ (Brabender Unit).

If used Flourgraph-E6 Haubelt (Haubelt model, Berlin, Germany) (ICC Standard No 179. (2010)) dough consistency must be 500 HE (Haubelt Unit).Extensograph Brabender (Duisburg, Germany) and Flourgraph E7(Haubel model, Berlin, Germany), gave the resistance to constant deformation, extensibility, the ratio, energy, maximum resistance, ratio number and ratio number max, in conformity table no. 1

Table 1 Name of parameter Extensograph Brabender (AACC Method 54-10, 2000) and Flourgraph E7 (ICC Standard 180 (2010).)

\begin{tabular}{lcccc}
\hline $\begin{array}{l}\text { Brabender } \\
\text { Extensograph (B) }\end{array}$ & UM & UM & $\begin{array}{c}\text { Flourgraph E7 } \\
(\mathbf{E})\end{array}$ & Symbol \\
\hline Energy & $\mathrm{cm}^{2}$ & $\mathrm{~cm}^{2}$ & Energy & - \\
\hline $\begin{array}{l}\text { Resistance to } \\
\text { extension }\end{array}$ & ${ }^{*} \mathrm{BU}$ & ${ }^{* *} \mathrm{HE}$ & $\begin{array}{c}\text { Resistance to } \\
\text { extension }\end{array}$ & $\mathrm{R}$ \\
\hline Extensibility & $\mathrm{mm}$ & $\mathrm{mm}$ & Extensibility & $\mathrm{E}$ \\
\hline Maxim Resistance & $\mathrm{BU}$ & $\mathrm{HE}$ & Maxim Resistance & $\mathrm{R}_{\mathrm{m}}$ \\
\hline Ratio number & - & - & Ratio number & $\gamma$ \\
\hline Ratio number(max) & - & - & $\begin{array}{c}\text { Ratio } \\
\text { number(max) }\end{array}$ & $\gamma_{\max }$ \\
\hline
\end{tabular}

*Brabender Unit; ${ }^{* * *}$ Haubelt Einheit(Unit)

The Extensograph and Flourgraph E7 procedure: It is done/made according to AACC and ICC. The level of water absorption in the presence of $2 \%$ salt is determined by using a Farinograph Brabender respectively Flourgraph E6 Haubelt. Dough consistency after 5 minutes will be 500 BU (Farinograph Brabender) or HE (Flourgraph E6). Dough is then mixed in a farinograph and then stretched in an extensograph. Dough weight is $150 \pm 0.1 \mathrm{~g}$. It is given a characteristic long rounded shape. The dough stretched by the extensograph hooks is kept for 45, 90, 135 minutes to allow the temperature to stabilise prior to tensile testing. Tensile behavior is recorded as a curve and the final results are stored as pdf files in the computer. The temperature for testing and thermostatic control is $30 \pm 2^{\circ} \mathrm{C}$.

The following algorithm was used for statistical interpretation and comparison of results It is done/made according to Pearson correlations coefficient and Student t-test.
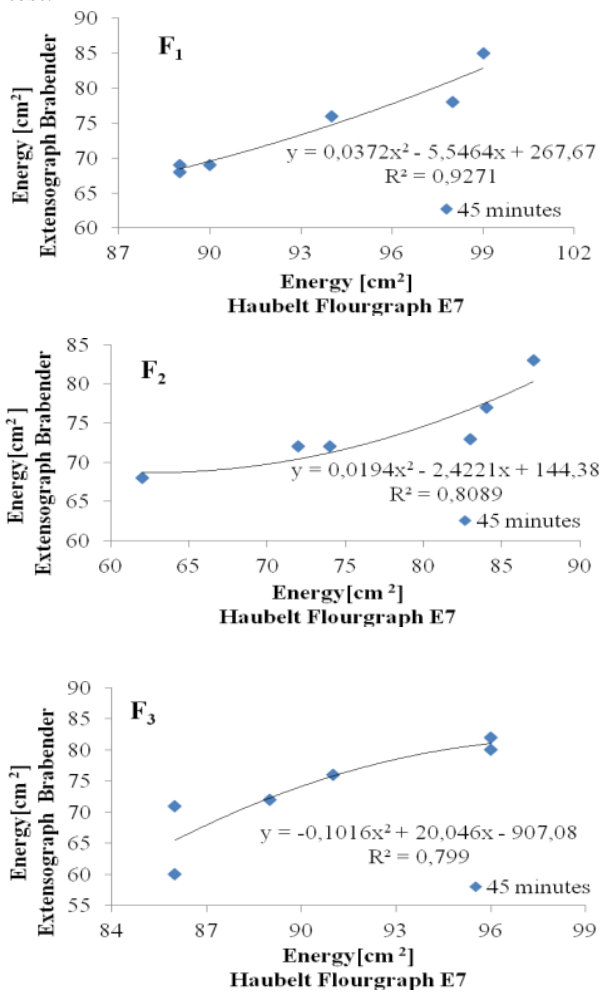

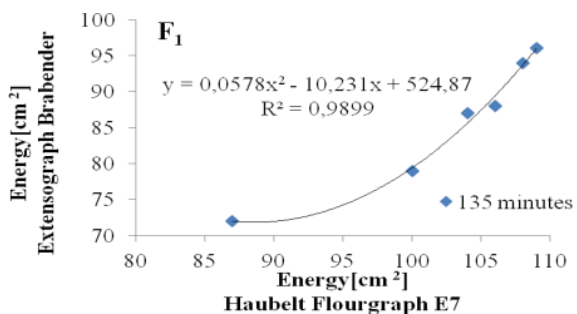

Haubelt Flourgraph $\mathrm{E7}$

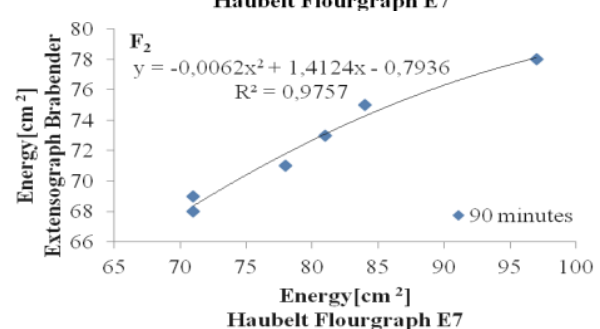

Haubelt Flourgraph $\mathrm{E} 7$

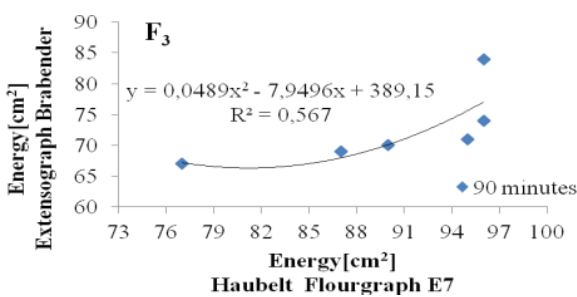

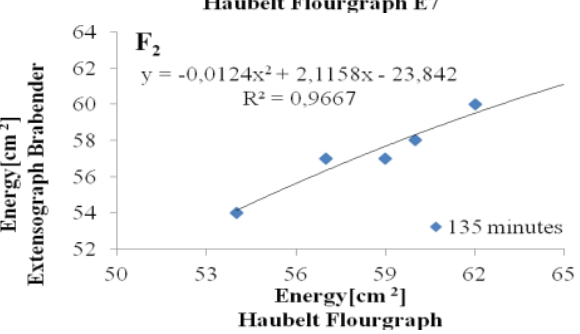

$\mathbf{F}_{3}$

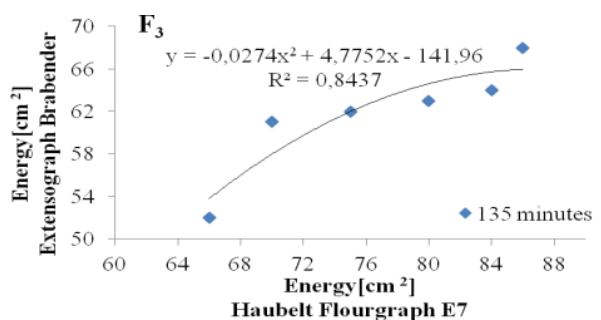

Figure 2 Scatter plot comparison and relationship between Brabender Extensograph and Flourgraph E7 value, for Energy using same method, for wheat flour $\mathrm{F}_{1}$; $\mathrm{F}_{2}$; $\mathrm{F}_{3}$ 
The quality of flour after $45,90,135$ minutes was found to be good for $F_{1}$ and $F_{2}$ and average for $\mathrm{F}_{3}$. A good correlation of values can be seen in one area of the scatter plot. The area under the curve, which is proportional to the energy required to stretch the test piece to its rupture point. This parameter, expressed in $\mathrm{cm}^{2}$, is a convenient single figure for characterizing flour strength. The stronger the flour, the more energy is required to stretch the dough (Dapcevic et al., 2011).
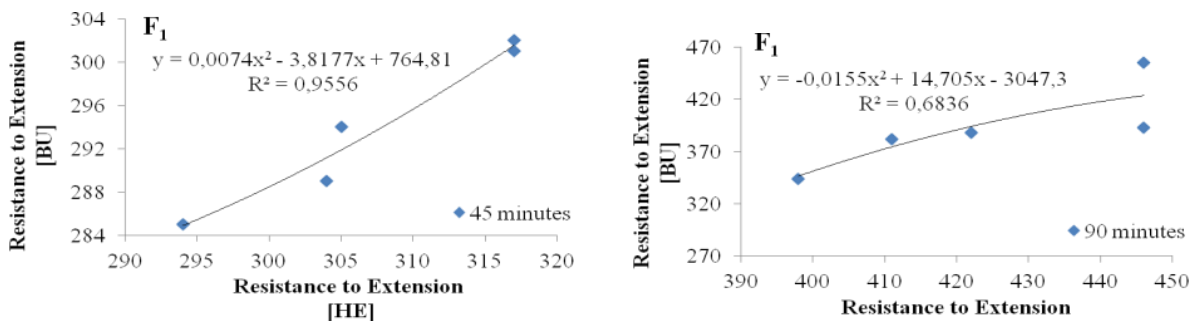

[HE]
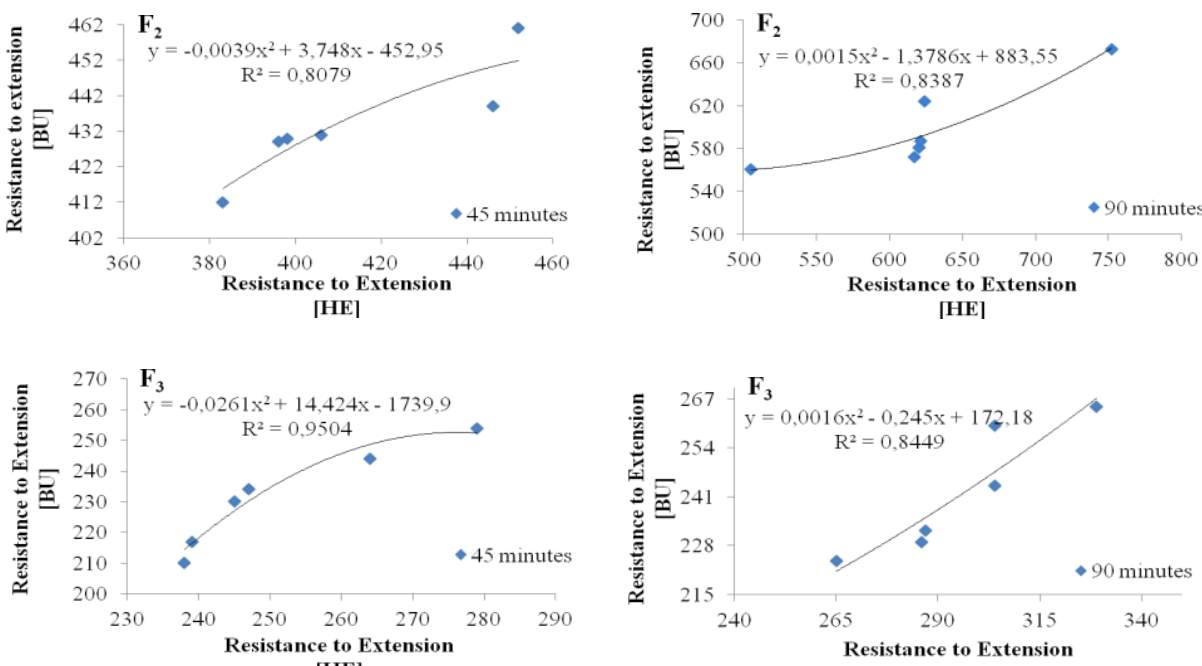

[HE]

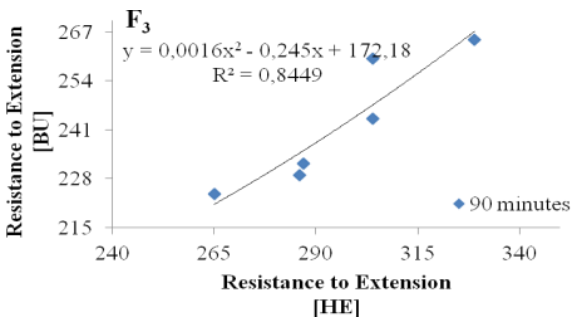

The best correlations obtained were: 0.98 for $F_{1}$ after 135 minutes, 0.9757 for $F_{2}$ after 90 minutes, and 0.84 for $\mathrm{F}_{3}$, after 135 minutes. The best correlation for al the flours studied and for the given energy values was obtained after 135 minutes of thermostatic control. The lowest correlation coefficients were obtained for $F_{1}$ after 90 minutes of thermostatic control, for $\mathrm{F}_{2}$ after 45 minutes and for $\mathrm{F}_{3}$ after 90 minutes.
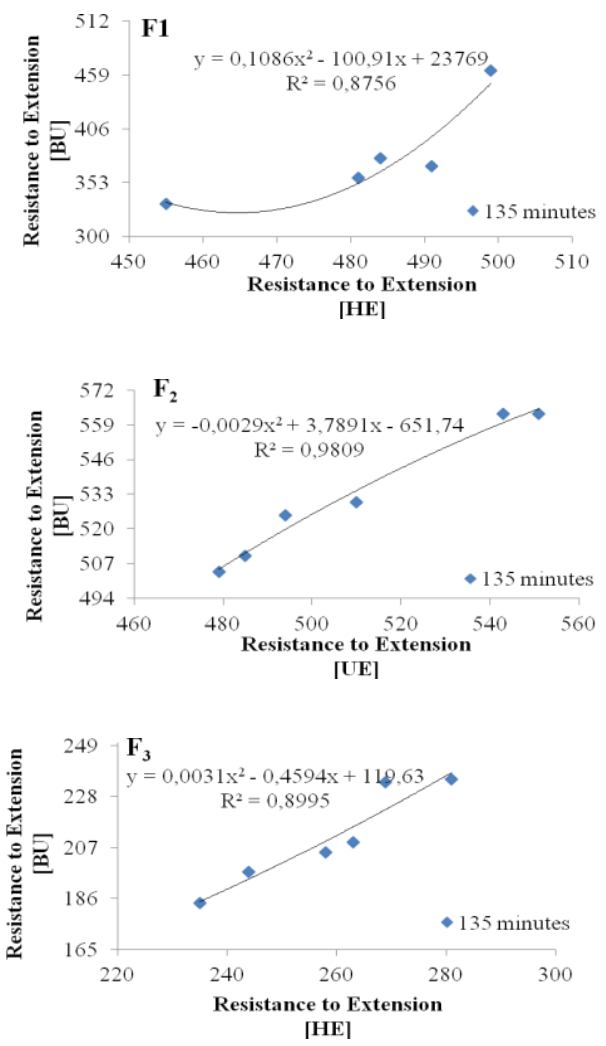

Figure 3 A scatter plot comparison and relationship between Brabender Extensograph and Flourgraph E7 value, for Resistance to Extension using the same method, for wheat flour $\mathrm{F}_{1} ; \mathrm{F}_{2} ; \mathrm{F}_{3}$.

Dough resistance to extension is plotted in Figure 3 and exhibits good correlation coefficients for the flours studied. While the dough was kept for its temperature to stabilize, the value of this parameter increased, and then it began to decrease

The best correlation was obtained after 45 minutes of thermostatic control for $F_{1}$ $\left(R^{2}=0.9556\right)$, after 135 minutes for $F_{2},\left(R^{2}=0.9809\right)$ and after 45 minutes for $F_{3}$ after 90 minutes.
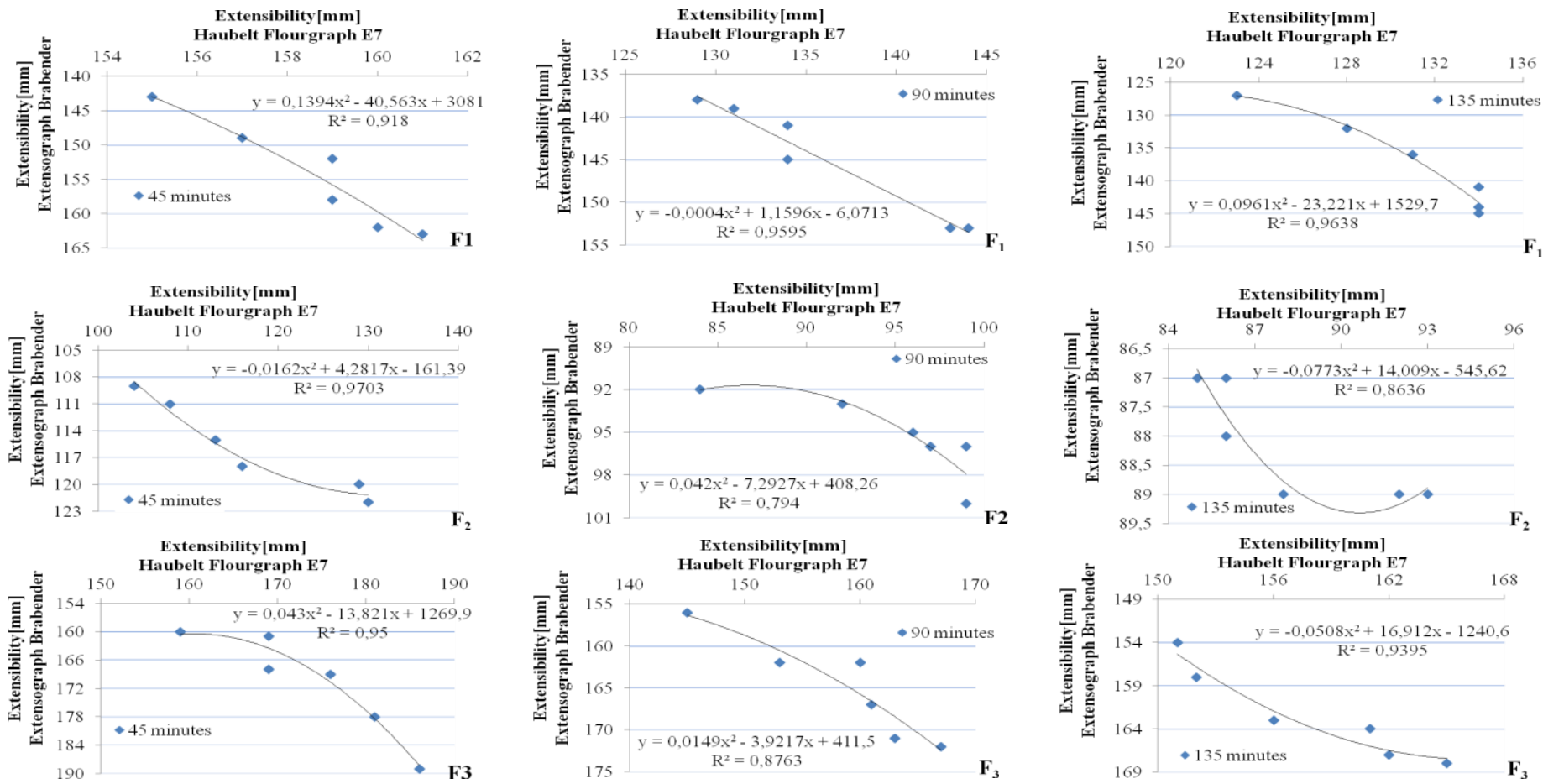

Figure 4 A scatter plot comparison and relationship between Brabender Extensograph and Flourgraph E7 value, for Extensibility using the same method, for wheat flour $\mathrm{F}_{1} ; \mathrm{F}_{2} ; \mathrm{F}_{3}$. 
The dough extensibility (E) expressed in $\mathrm{mm}$, which represents the distance of stretching before rupture (Dapcevic et al., 2011). The polynomial regression values obtained are plotted in Figure 4. The correlations were found to be positive, very good, between the values obtained for all the flours studied and at the set thermostatic control times. The lowest correlation was obtained for $\mathrm{F}_{2}$ after 90 minutes and the best for $\mathrm{F}_{2}$ after 45 minutes of thermostatic control.

The maximum resistance $\left(\mathrm{R}_{\max }\right)$ or the resistance at constant deformation usually corresponds to the height of the curve at $50 \mathrm{~mm}$ from the beginning of stretching $\left(\mathrm{R}_{50}\right)$ (Bordei, 2007). The latter is preferably expressed within the cereal testing laboratories since it represents the resistance at a fixed extension for all tested doughs. This parameter is expressed in Brabender units (Dapcevic et al., 2011).
In table 2 data are shown for, maximum resistance and Pearson Correlations coefficients. For $F_{1}$ the maximum resistance has been correlated thus: at the 45 minutes is a strong positive correlations at the 90 minutes is a strong positive correlations and at the 135 minutes is a moderate positive correlations. For $\mathrm{F}_{2}$ the maximum resistance has been correlated thus: at the 45 minutes is a strong positive correlations, at the 90 minutes was a strong positive correlations and at the 135 minutes is a strong positive correlations. For $\mathrm{F}_{3}$ the maximum resistance has been correlated thus: at the 45 minutes is a strong positive correlations, at the 90 minutes is a strong positive correlations and at the 135 minutes is a strong positive correlations.

Table 2 Experimental value and theoretical statistical interpretation correlations index for Resistance maxium

\begin{tabular}{|c|c|c|c|c|c|c|c|c|c|c|}
\hline \multirow[b]{3}{*}{ Sample } & \multirow[b]{3}{*}{ Device } & \multicolumn{9}{|c|}{ Proving time [min] } \\
\hline & & \multicolumn{3}{|c|}{45} & \multicolumn{3}{|c|}{90} & \multicolumn{3}{|c|}{135} \\
\hline & & $\begin{array}{l}\text { Real value } \\
\text { Resistance } \\
\text { maxim }\end{array}$ & $\mathrm{R}^{2}$ & $\mathrm{r}$ & $\begin{array}{l}\text { Real value } \\
\text { Resistance } \\
\text { maxim }\end{array}$ & $\mathrm{R}^{2}$ & $\mathrm{r}$ & $\begin{array}{l}\text { Real value } \\
\text { Resistance } \\
\text { maxim }\end{array}$ & $\mathrm{R}^{2}$ & $\mathrm{r}$ \\
\hline \multirow{2}{*}{$\mathrm{F} 1$} & B & $\begin{array}{c}348.3 \pm 12.32 \\
{[\mathrm{BU}]}\end{array}$ & \multirow{2}{*}{0.8006} & \multirow{2}{*}{0.8948} & $\begin{array}{c}435.6 \pm 34.62 \\
{[\mathrm{BU}]}\end{array}$ & \multirow{2}{*}{0.918} & \multirow{2}{*}{0.9581} & $\begin{array}{c}438 \pm 39.38 \\
{[\mathrm{BU}]}\end{array}$ & \multirow{2}{*}{0.363} & \multirow{2}{*}{0.6025} \\
\hline & $\mathrm{E}$ & $\begin{array}{c}389.33 \pm 14.38 \\
{[\mathrm{HE}]}\end{array}$ & & & $\begin{array}{c}501.8 \pm 11.02 \\
{[\mathrm{HE}]}\end{array}$ & & & $\begin{array}{c}545.5 \pm 43.34 \\
{[\mathrm{HE}]}\end{array}$ & & \\
\hline \multirow{2}{*}{$\mathrm{F} 2$} & B & $\begin{array}{c}471.5 \pm 16.43 \\
{[\mathrm{BU}]}\end{array}$ & \multirow{2}{*}{0.9484} & \multirow{2}{*}{0.9739} & $\begin{array}{c}600.6 \pm 22.79 \\
{[\mathrm{BU}]}\end{array}$ & \multirow{2}{*}{0.620} & \multirow{2}{*}{0.7876} & $\begin{array}{c}544.66 \pm 21.36 \\
{[\mathrm{BU}]}\end{array}$ & \multirow{2}{*}{0.9708} & \multirow{2}{*}{0.9853} \\
\hline & $\mathrm{E}$ & $\begin{array}{c}475.5 \pm 26.84 \\
{[\mathrm{HE}]}\end{array}$ & & & $\begin{array}{c}635.8 \pm 62.13 \\
{[\mathrm{HE}]}\end{array}$ & & & $\begin{array}{c}523.5 \pm 25.21 \\
{[\mathrm{HE}]}\end{array}$ & & \\
\hline \multirow{2}{*}{ F3 } & B & $\begin{array}{c}323.33 \pm 11.97 \\
{[\mathrm{BU}]}\end{array}$ & \multirow{2}{*}{0.6824} & \multirow{2}{*}{0.8261} & $\begin{array}{c}323.12 \pm 2.64 \\
{[\mathrm{BU}]}\end{array}$ & \multirow{2}{*}{0.7078} & \multirow{2}{*}{0.8413} & $\begin{array}{c}284 \pm 17.11 \\
{[\mathrm{BU}]}\end{array}$ & \multirow{2}{*}{0.9362} & \multirow{2}{*}{0.9676} \\
\hline & $\mathrm{E}$ & $\begin{array}{c}363.16 \pm 11.9 \\
{[\mathrm{HE}]}\end{array}$ & & & $\begin{array}{c}339.66 \pm 56 \\
{[\mathrm{HE}]}\end{array}$ & & & $\begin{array}{c}339.33 \pm 28.88 \\
{[\mathrm{HE}]}\end{array}$ & & \\
\hline
\end{tabular}

B - Brabender Extensograph; E - Flourgraph E7. The significance threshold was $\alpha=0.05$ and standard deviation represented on the graph was calculated based on 6 flourgrams and 6 extensograms

Table 3 Experimental value and theoretical statistical interpretation correlations index for Ratio number

\begin{tabular}{|c|c|c|c|c|c|c|c|c|c|c|}
\hline \multirow{3}{*}{ Sample } & \multirow{3}{*}{ Device } & \multicolumn{9}{|c|}{ Proving time [min] } \\
\hline & & \multicolumn{3}{|c|}{45} & \multicolumn{3}{|c|}{90} & \multicolumn{3}{|c|}{135} \\
\hline & & Real value & $\mathrm{R}^{2}$ & $\mathrm{r}$ & Real value & $\mathrm{R}^{2}$ & $\mathrm{r}$ & Real value & $\mathrm{R}^{2}$ & $\mathrm{r}$ \\
\hline \multirow[b]{2}{*}{$\mathrm{F} 1$} & B & $1.96 \pm 0.196$ & \multirow[b]{2}{*}{0.7693} & \multirow[b]{2}{*}{0.871} & $2.68 \pm 0.352$ & \multirow[b]{2}{*}{0.89} & \multirow[b]{2}{*}{0.9434} & $2.93 \pm 0.33$ & \multirow[b]{2}{*}{0.574} & \multirow[b]{2}{*}{0.7576} \\
\hline & $\mathrm{E}$ & $1.9 \pm 0.132$ & & & $3.23 \pm 0.2$ & & & $2.68 \pm 0.352$ & & \\
\hline \multirow[b]{2}{*}{$\mathrm{F} 2$} & B & $3.75 \pm 0.33$ & \multirow[b]{2}{*}{0.8313} & \multirow[b]{2}{*}{0.9121} & $6.3 \pm 1.1$ & \multirow[b]{2}{*}{0.8361} & \multirow[b]{2}{*}{0.9144} & $5.93 \pm 0.7$ & \multirow[b]{2}{*}{0.8138} & \multirow[b]{2}{*}{0.9021} \\
\hline & $\mathrm{E}$ & $3.58 \pm 0.79$ & & & $6.6 \pm 0.39$ & & & $5.86 \pm 0.748$ & & \\
\hline \multirow[b]{2}{*}{ F3 } & B & $1.38 \pm 0.23$ & \multirow[b]{2}{*}{0.7408} & \multirow[b]{2}{*}{0.8607} & $1.43 \pm 0.09$ & \multirow[b]{2}{*}{0.5618} & \multirow[b]{2}{*}{0.7495} & $1.302 \pm 0.184$ & \multirow[b]{2}{*}{0.7735} & \multirow[b]{2}{*}{0.8795} \\
\hline & $\mathrm{E}$ & $1.5 \pm 0.352$ & & & $1.88 \pm 0.33$ & & & $1.633 \pm 0.206$ & & \\
\hline
\end{tabular}

B - Brabender Extensograph; E - Flourgraph E7. The significance threshold was $\alpha=0.05$ and standard deviation represented on the graph was calculated based on 6 flourgrams and 6 extensograms

Table 4 Experimental value and theoretical statistical interpretation correlations index for Ratio number max

\begin{tabular}{|c|c|c|c|c|c|c|c|c|c|c|}
\hline \multirow{3}{*}{ Sample } & \multirow{3}{*}{ Device } & \multicolumn{9}{|c|}{ Proving time [min] } \\
\hline & & \multicolumn{3}{|c|}{45} & \multicolumn{3}{|c|}{90} & \multicolumn{3}{|c|}{135} \\
\hline & & Real value & $\mathrm{R}^{2}$ & $\mathrm{r}$ & Real value & $\mathrm{R}^{2}$ & $\mathrm{r}$ & Real value & $\mathrm{R}^{2}$ & $\mathrm{r}$ \\
\hline \multirow[b]{2}{*}{$\mathrm{F} 1$} & B & $2.26 \pm 0.09$ & \multirow{2}{*}{0.7562} & \multirow{2}{*}{0.8696} & $3.01 \pm 0.37$ & \multirow{2}{*}{0.9602} & \multirow{2}{*}{0.9799} & & \multirow{2}{*}{0.7887} & \multirow{2}{*}{0.8881} \\
\hline & $\mathrm{E}$ & $2.46 \pm 0.154$ & & & $3.78 \pm 0.16$ & & & & & \\
\hline \multirow[b]{2}{*}{$\mathrm{F} 2$} & B & $4.07 \pm 0.13$ & \multirow{2}{*}{0.8122} & \multirow{2}{*}{0.9012} & $6.37 \pm 0.45$ & \multirow{2}{*}{8398} & \multirow{2}{*}{0.9164} & $6.03 \pm 0.24$ & \multirow{2}{*}{0.8497} & \multirow{2}{*}{0.9218} \\
\hline & $\bar{E}$ & $3.32 \pm 0.73$ & & & $6.72 \pm 0.77$ & & & $3.18 \pm 0.35$ & & \\
\hline \multirow[b]{2}{*}{ F3 } & $\mathrm{B}$ & $1.93 \pm 0.132$ & \multirow{2}{*}{0.6964} & \multirow{2}{*}{0.8345} & $2 \pm 0.08$ & \multirow{2}{*}{0.9803} & \multirow{2}{*}{0.9901} & $4.26 \pm 0.088$ & \multirow{2}{*}{0.5149} & \multirow{2}{*}{0.7176} \\
\hline & $\mathrm{E}$ & $2.1 \pm 0.15$ & & & $2.22 \pm 0.38$ & & & $2.13 \pm 0,07$ & & \\
\hline
\end{tabular}

$\mathrm{B}$ - Brabender extensograph; E - Flourgraph E7. The significance threshold was $\alpha=0.05$ and standard deviation represented on the graph was calculated based on 6 flourgrams and 6 extensogras

In the ratio of resistance to extensibility, high ratio indicates the short gluten properties resulting in low volume of baked products (Dapcevic et al., 2011).

In table 3 data are shown for, Ratio number and Pearson Correlations coefficients. For $F_{1}$ the ratio number has been correlated thus: at the 45 minutes is a moderate positive correlations, at the 90 minutes is a strong positive correlations and at the 135 minutes is a moderate positive correlations. For $F_{2}$ the ratio number has been correlated thus: at the 45 minutes is a strong positive correlations, at the 90 minutes was a strong positive correlations and at the 135 minutes is a strong positive correlations. For $\mathrm{F}_{3}$ the ratio number has been correlated thus: at the 45 minutes is a strong positive correlations, at the 90 minutes is a moderate positive correlations and at the 135 minutes is a strong positive correlations.
In table 4 data are shown for, ratio number max. and Pearson Correlations coefficients. For $F_{1}$ the ratio number max. has been correlated thus: at the 45 minutes is a strong positive correlations, at the 90 minutes is a strong positive correlations and at the 135 minutes is a strong positive correlations. For $\mathrm{F}_{2}$ the ratio number has been correlated thus: at the 45 minutes is a strong positive correlations, at the 90 minutes was a strong positive correlations and at the 135 minutes is a strong positive correlations. For $\mathrm{F}_{3}$ the ratio number has been correlated thus: at the 45 minutes is a strong positive correlations, at the 90 minutes is a strong positive correlations and at the 135 minutes is a strong positive correlations 


\section{CONCLUSION}

Through experimental value and theoretical statistical interpretation correlations index for parameter Extensograph Brabender and Flourgraph E7 was made the following conclusions were reached:

- the values of dough hydration capacity were found to be different but close, depending on the mixing bowl capacity, which influences the

degree of dissipation of dough strength,

- a good correlation was found between the values of the measured variables characterizing the viscoelastic properties of dough energy,

resistance to extension, extensibility, maximum resistance, ratio and maximum ratio,

- the values of the correlation index were found to range between 0.8 and 0.9 ,

with a few exceptions,

- there was found to be a close correlation between the measured rheological properties of dough: ratio, maximum ratio and maximum

resistance.

- the maximum values are for resistance maxim, for $\mathrm{F}_{2}(\mathrm{r}=0.9853)$, ratio number, for $F_{2}(r=0.9121)$ and ratio number max., for $F_{2}$

$(\mathrm{r}=0.9218)$ at 135 minutes.

Both devices can be used successfully to characterize dough-like colloidal mixtures as half-finished products in bread manufacturing.

Acknowledgements: The authors gratefully acknowledge the support from the Haubelt Laborgeräte GmbH Garten felder str.13599 Berlin, Germany, particularly the engineer Haubelt Günter.

\section{REFERENCES}

Astha, R., Masih Dorcus, M. (2014). Physico Chemical and Rheological Properties of Wheat Flour Bun Supplemented with Orange Peel Powder, International Journal of Science and Research, Volume 3 Issue 8, www.ijsr.net.

Sahraiyan, B., Naghipour, F., Karimi, M., Davoodi, M.G. (2013). Evaluation of Lepidium sativum seed and guar gum to improve dough rheology and quality parameters in composite riceewheat bread, Food Hydrocolloids 30, 698-703. http://dx.doi.org/10.1016/j.foodhyd.2012.08.013

Bloksma, A.H, \& Bushuk, H. W. (1988). Rheology and chemistry of dough Chemistry and Technology, $3^{\text {rd }}$ ed., vol. II, Y. Pomeranz, ed. Am Assoc. Cereal Chem., St. Paul, MN, pag. 131-217

Bordei, D. coordinator. (2007). Quality control in the baking industry. Methods of analysis, Ed. Academica Galați Cereal Food World, January-February. (2007), vol.52, No.1, p:33.

Dapcevic, T. H, Pojic, M., Hadnađev, M., and Torbica, A. (2011). The Role of Empirical Rheology in Flour Quality Control, Wide Spectra of Quality Control, Dr. Isin Akyar (Ed.), ISBN: 978-953-307-683-6

Iancu, M. L., Mike, L, Haubelt, G. (2011). Research on the rheometric elements of the potato dough and the influence of measured variables upon bread quality, Journal of Agroalimentary Processes and Technologies, 17(2), 199-206 Journal Site: http://journal-of-agroalimentary.ro

Jbeily, A.C., Haubelt, G., Myburgh, J., Svacinka, R.(2014 a). Results of an international ring test for the determination of water absorption capacity and physical properties of wheat dough using the Haubelt Flourgraph E 6 (ICC standard no. 179). Quality Assurance and Safety of Crops \& Foods, Online Date Friday, July 25 http://dx.doi.org/10.3920/qas2013.0288

Jbeily, A.C., Haubelt, G.,Myburgh J., Svacinka, R. (2014 b). Results of an international ring test for the determination of the rheological properties of wheat flour dough using the Haubelt Flourgraph E 7 (ICC standard no. 180.) Quality Assurance and Safety of Crops \& Foods, Online Date Thursday May 22, http://dx.doi.org/10.3920/qas2013.0289

Kahraman, K., Sakyyan, O., Ozturk, S., Koksel, H., Sumnu, G. And, Dubat, A. (2008). Utilization of mixolab to predict the suitability of flours in terms of cake quality. European Food Research Technology, 227, 565-570, http://dx.doi.org/10.1007/s00217-007-0757-y

Thu, M., Day L. (2013). Effect of sodium chloride on gluten network formation, dough microstructure and rheology in relation to breadmaking, Journal of Cereal Science, 57 444-452, http://dx.doi.org/10.1016/j.jcs.2013.01.011

Moss, H. J. (1980). Strength requirements of doughs destined for repeated sheeting compared with those of normal doughs. Cereal chem., pp. 57, 195

Müller, H.G., Williams, M.V., Russell E., P.W., Coppock, J.B.M. (1961) Fundamental studies on dough with the Brabender Extensograph. I Determination of stress-strain curves. J.Sci. Food Agric., 12: 513 http://dx.doi.org/10.1002/jsfa.2740120703

Preston, K.R., Hoseney, R.C. (1998). Appllication of the Extensigraph, Chapter III in The Extensigraph Handbook published by the American Association Of Cereal Chemists, Inc St Paul, Minnesota, USA, pp.13.

Tong, Q., Zhang, X., Wu, F., Tong, J., Zhang, P., Zhang, J. (2010). Effect of honey powder on dough rheology and bread quality, Food Research International, 43, 2284-2288, http://dx.doi.org/10.1016/j.foodres.2010.08.002.

Rapsen, F.V., Preston, K.R. (1991). The extensigraph handbook, St Paul, Minnesota: American Association of Cereal Chemist
Sharoba, A.M., Farrag, M.A., Abd El-Salam, A.M. (2013). Utilization of some fruits and vegetables waste as a source of dietary fiber and its effect on the cake making and its quality attributes, Journal of Agroalimentary Processes and Technologies, 19(4), $429-444$.

Song, M.R., Lee, K.S., Bycong-Chan, L., Man-Jin O. (2007). Quality and Sensory characteristics of White Bread added with various Ginseng Products, Korean J. Food Preserv.14(4), 369-377, http://dx.doi.org/10.3746/jkfn.2007.36.10.1307

Tabilo-Munizaga, G., Barbos, C. (2005). Rheology for the food industry. Journal of Food Engineering, 67, 147-156, http://dx.doi.org/10.1016/j.jfoodeng.2004.05.062.

Tanaka, K., Furukawa, K., Matsumoto, H. (1967 b). The effect of acid and salt on the farinogram and extensigram of dough. Cereal Chem. 44, 675

Zaharia, D., Danciu, I., Codină, G., Mironeasa, S., Mironeasa, C. (2014). Use of principal component analysis in assessment of relationship between technological and rheological parameters of wheat flour, Journal of Food, Agriculture \& Environment 12 (1), $29-32$.

www.socstatistics.com/test/pearson

SR 90 : 2007, Wheat flour. Analytical methods.

ICC Standard No. 104/1.(1990). Determination of Ash in Cereals and Cereal Products.

ICC Standard No.106/2. (1984). Working Method for the Determination of Wet Gluten in Wheat Flour

ICC Standard No.107/1. (1995). Determination of the "Falling Number" according to Hagberg - as a Measure of the Degree of Alph

Amylase Activity in Grain and Flour Alpha-Amylase Activity (Falling Number). ICC Standard No. 110/1.(1976). Determination of the Moisture Content of Cereals and Cereal Products (Practical method).

ICC Standard No. 114/1.(1992). Method for using the Brabender Extensograph.

AACC Method 54-10.(1995). Method for using the Brabender Extensograph.

ICC Standard No. 115/1.(1992). Method for using the Brabender Farinograph.

AACC Method 54-21.(1995). Method for using the Brabender Farinograph

ICC Standard No 179. (2010). for ICC procedure based Flourgraph E6, Determination of Water Absorption Capacity of Wheat Flours and

Physical Properties of Wheat Flour Dough Using the Flourgraph E6 ("Farino"). ICC Standard No 180. (2010). For ICC procedure based Flourgraph E7. 